\title{
GERENCIAMENTO DE PROJETOS EM EMPRESAS JUNIORES: ANÁLISE DO CONTEXTO GERENCIAL BRASILEIRO
}

\author{
PROJECT MANAGEMENT IN JUNIOR COMPANIES: ANALYSIS OF THE BRAZILIAN \\ MANAGEMENT CONTEXT
}

Anita Marcondes Luz Vissotto Administradora Universidade Federal de Uberlândia (UFU) Uberlândia, MG - Brasil anitamlvissotto@gmail.com

\author{
Vérica Freitas \\ Doutora em Engenharia de Produção \\ Universidade de São Paulo (USP) \\ Professora Associada da Universidade Federal de Uberlândia (UFU) \\ Uberlândia, MG - Brasil \\ verica@ufu.br \\ Guilherme André Braga \\ Mestre em Administração \\ Universidade Federal de Uberlândia (UFU) \\ Uberlândia, MG - Brasil \\ guilhermebraga26@hotmail.com \\ Verônica Angélica Freitas de Paula \\ Doutora em Engenharia de Produção \\ Universidade Federal de São Carlos (UFSCar) \\ Professora Associada da Universidade Federal de Uberlândia (UFU) \\ Uberlândia, MG - Brasil \\ veronica@ufu.br
}

\begin{abstract}
Resumo
As Empresas Juniores (EJs) contribuem para a formação profissional de graduandos por meio, principalmente, da realização de projetos, atuando também como uma fonte de acesso a soluções e novas tecnologias, em especial, para micro e pequenos empresários, sendo importante discutir o Gerenciamento de Projetos nessas organizações. Dessa forma, este estudo visa compreender as particularidades e as necessidades das EJs em relação ao Gerenciamento de Projetos e oferecer insights que possam contribuir com essas organizações. Para tanto, foi realizado um estudo de caso múltiplo com seis EJs, seguido de uma survey conduzida com EJs brasileiras com 12\% de taxa de resposta. Foi possível identificar a importância de um bom diagnóstico organizacional, bem como as expectativas e as necessidades dos clientes para posterior realização dos projetos. Além disso, é fundamental um planejamento inicial bem estruturado do projeto, com escopo e cronograma definidos, mas que sejam passíveis de revisão quando necessário, sendo relevante a participação ativa dos clientes durante o projeto.
\end{abstract}

Palavras-chave: Gerenciamento de projetos. Empresa Júnior. Fatores críticos de sucesso.

Abstract

Junior Companies (EJs in Portuguese) contribute to the professional training of undergraduates mainly through the development of projects, also acting as a source of access to solutions and new technologies mostly for micro and small entrepreneurs, so it is important to discuss Project Management in these organizations. Thus, this study aims to understand the particularities and needs of EJs in relation to Project Management and offer insights that can contribute to these organizations. To accomplish this, a multiple case study was carried out with six EJs, followed by a survey with Brazilian EJs at a $12 \%$ response rate. It was possible to identify the importance of good organizational diagnosis, identifying the clients' expectations and needs for the subsequent development of the projects. In addition, it is essential to have a wellstructured initial planning of the project, with defined scope and schedule, but subject to review when necessary, requiring the active participation of the clients during the project.

Keywords: Project management. Junior company. Success critical factors.

\section{Cite como}

American Psychological Association (APA)

Vissotto, A. M. L., Freitas, V., Braga, G. A., \& Paula, V. A. F. (2021, maio/ago.). Gerenciamento de projetos em empresas juniores: análise do contexto gerencial brasileiro. Revista de Gestão e Projetos (GeP), 12(2), 135-162. https://doi.org/10.5585/gep.v12i2.17984. 


\section{Introdução}

O Gerenciamento de Projetos é intrínseco ao ser humano desde os primórdios da civilização. Da construção das pirâmides do Egito, passando pela Revolução Industrial no Século XIX até as colossais construções civis e projetos biotecnológicos de escala global atualmente, os Projetos estão presentes com o intuito de criar produtos ou serviços, bem como para introduzir e implementar inovações em processos organizacionais. A exigência é cada vez maior nos arranjos organizacionais contemporâneos, sendo fundamentais a aplicação e o aprimoramento dos princípios do Gerenciamento de Projetos (Marcondes, 2017).

Para Söderlund e Lenfle (2013), é de suma importância estudar e analisar a diversidade técnica, os instrumentos $\mathrm{e}$ as abordagens envolvidos em qualquer projeto com o intuito de aperfeiçoar as práticas modernas e, assim, superar os desafios operacionais que são cada vez mais complexos.

Considerando que as organizações devem melhorar o gerenciamento de seus Projetos em um cenário cada vez mais complexo e competitivo, o Movimento Empresa Júnior (MEJ) torna-se um importante alicerce para a modernização dos processos relacionados ao Gerenciamento de Projetos. As Empresas Juniores (EJs) têm como objetivo prestar serviços e soluções de consultoria em suas áreas de atuação determinadas pelos cursos de graduação como forma de desenvolver tantos estudantes, por meio da aplicação prática, como organizações, geralmente, micro e pequenos empresas, que demandam melhores práticas de gestão e operações.

De acordo com o Serviço Brasileiro de Apoio às Micro e Pequenas Empresas - Sebrae (2019), a taxa de empreendedorismo no Brasil foi de 38\% em 2018, significando que há cerca de 52 milhões de pessoas na condição de empreendedor em estágio inicial ou já estabelecido, com ampla maioria atuando com micro e pequenas empresas (MPE). Nesse sentido, é perceptível o potencial de empreendedorismo do país, sendo necessário um planejamento bem estruturado para maximizar as chances de sobrevivência dessas organizações, principalmente, na sua fase inicial. Uma das formas para alcançar esses objetivos é contar com o apoio técnico dos serviços de consultoria, ramo em que as EJs estão inseridas (King, Burke, \& Pemberton, 2005). Aliás, as MPEs são as principais clientes das EJs, inclusive, em virtude do preço dos projetos, que tornam os serviços oferecidos pelas EJs mais acessíveis para as MPEs.

A EJ, por mais que seja um ambiente de aprendizagem, apresenta as mesmas demandas de uma empresa padrão, mas com a realização do trabalho guiada por estudantes que não têm a experiência. Assim, é fundamental a participação de alunos comprometidos e o uso de ferramentas eficazes para alcance de resultados com a maior assertividade possível (Ziliotto \& Berti, 2012). Entre as ferramentas 
utilizadas, as EJs utilizam modelos de Gerenciamento de Projetos já existentes, pois, considerando as limitações e as experiências dos membros das EJs, tais modelos prédefinidos são menos susceptíveis a erros, além de já haver um método de aplicação já consolidado.

Tendo em vista esse cenário, pode ser de grande valia desenvolver modelos de Gerenciamento de Projetos já adaptados para EJs que considerem suas peculiaridades. Nesse sentido, Freitas e Paula (2016) citam que ainda há espaço para mudanças e estruturação de novos processos a serem implementados para que as EJs do Brasil melhorem a sua atual sistemática da organização. Essas adaptações podem proporcionar um significativo aumento no desempenho das EJs e potencializar as chances de sucesso na realização de projetos.

Dessa forma, este estudo visa compreender as particularidades e as necessidades das EJs em relação ao Gerenciamento de Projetos e oferecer insights que possam contribuir com essas organizações, que colaboram com a formação de profissionais.

\section{Referencial teórico}

Visando contribuir para a consecução do objetivo proposto e a discussão das temáticas em análise, o Referencial Teórico deste estudo traz conceitos sobre o Movimento Empresa Júnior e o Gerenciamento de Projetos.

\subsection{Movimento empresa Júnior}

O MEJ surgiu em 1967 na França, chegando ao Brasil em 1988, sendo a Fundação Getúlio Vargas (FGV) e a Politécnica da Universidade de São Paulo (USP) suas precursoras (Salomão, 2014; Ereno, 2013). A partir daí, houve uma grande adesão ao MEJ no Brasil, com 805 empresas constituídas em 2018 (Brasil Júnior, 2020a), envolvendo 22 mil graduandos brasileiros em 2018 (Diário do Comércio, 2019). Tais dados colocam o Brasil como o país com maior quantidade de EJs no mundo, superando, inclusive, o continente europeu (Pamplona \& Freitas, 2016). Legalmente, conforme dispõe a Lei n. 13.267, (Brasil, 2016, p. 1), EJ é uma “associação civil gerida por estudantes matriculados em cursos de graduação de instituições de ensino superior, com o propósito de realizar projetos e serviços que contribuam para o desenvolvimento acadêmico e profissional dos associados, capacitando-os para o mercado de trabalho".

O MEJ é composto por confederações, quando analisado em âmbito nacional, federações, na atuação nos estados, núcleos, que atuam em cidades ou universidades e EJs, quando considerados os cursos de graduação, podendo ser constituídas por um curso ou mais (Matos, 1997).

A principal missão do MEJ, de acordo com Brasil Júnior (2020c), é formar empreendedores comprometidos e capazes de transformar o Brasil por meio da vivência empresarial, e isso ocorre por meio da realização de mais e melhores projetos. Entre 
os principais objetivos das EJs, Guimarães, Moreira e Baeta (2013) destacam: gerar a oportunidade de aplicação, na prática, dos conhecimentos teóricos relacionados à área de formação; desenvolver a capacidade crítica, analítica e empreendedora dos alunos; intensificar o relacionamento com a instituição de ensino; facilitar o ingresso no mercado de trabalho; contribuir com a sociedade, proporcionando um serviço de qualidade a preços acessíveis; não priorizar a captação de lucro como objetivo principal, mas promover a consolidação do conhecimento dos seus integrantes.

Franco e Seibert (2017) também destacam que as EJs podem ser vistas como uma iniciativa de aprendizagem andragógica, contribuindo com o desenvolvimento dos estudantes de graduação, favorecendo a autonomia dos alunos, promovendo o aprimoramento de habilidades, como a liderança e responsabilidade, e despertando o interesse nos alunos em aprender mais, inclusive, para atuar nos projetos.

De acordo com Matos (1997), as EJs são uma grande oportunidade de para a criação de relacionamentos entre os universitários, as instituições de ensino como um todo e o mercado, além de propiciar o desenvolvimento das pessoas que compõem o seu quadro social como empreendedores. Dornelas (2008, p. 189) corrobora essa visão, considerando as EJs como influenciadoras do empreendedorismo, afirmando também que "são uma alternativa de baixo custo e boa qualidade para as pequenas empresas, pois sempre têm o respaldo de professores que auxiliam os alunos na resolução dos problemas".

Devido ao reconhecido suporte no auxílio externo de planejamento para empreendedores que pretendem abrir, expandir ou reestruturar seu negócio e para a formação de novos empreendedores por meio da vivência empresarial dos universitários, as EJs se consolidam cada vez como uma efetiva ferramenta educacional no país. Em 2018, foram realizados mais de 18 mil projetos e as EJ faturaram mais de R \$ 29 milhões (Brasil Júnior, 2020b).

Para alcançar os números mencionados, a Brasil Júnior (BJ), inicialmente, implantou, entre 2013 e 2015, o Programa de Excelência em Gestão (PEG), que objetivou avaliar o desempenho das empresas que integram o MEJ e capacitar os empresários juniores, considerando alguns fatores inerentes (Brasil Júnior, 2014). Em 2016, a BJ reformulou seu planejamento estratégico para direcionar os esforços das federações, núcleos e EJs para um objetivo em comum: aumentar a frequência e o nível de excelência dos projetos realizados. A partir desse momento de maior exigência técnica, o Gerenciamento de Projetos passou a ser uma ferramenta determinante para as EJs (Brasil Júnior, 2020d).

\subsection{Gerenciamento de projetos}

De acordo com Kerzner (2006), um projeto é definido como um empreendimento exclusivo, com um começo e um fim, 
estabelecido sob um objetivo bem definido, o que consome recursos e opera sob pressão de prazos, custos e qualidade. Tendo em vista que os projetos estão cada vez mais complexos, requerendo conhecimentos e habilidades interfuncionais, o Gerenciamento de Projetos é fundamental, pois considera o planejamento, a organização, a direção e o controle dos recursos da empresa para a busca por alcançar um resultado em relativo prazo estabelecido para concluir objetivos específicos (Kerzner, 2011).

De acordo com o Project Management Institute - PMI (2017, p. 10), Gerenciamento de Projetos é "a aplicação de conhecimentos, habilidades, ferramentas e técnicas às atividades do projeto a fim de cumprir os seus requisitos. O Gerenciamento de Projetos é realizado através da aplicação e integração apropriadas dos processos de Gerenciamento de Projetos". Ainda de acordo com o PMI (2017), o Gerenciamento de Projetos considera os seguintes agrupamentos de processos de gerenciamento para atingir os objetivos específicos do projeto: iniciação; planejamento; execução; monitoramento e controle; e encerramento.

Para Kerzner (2006), o objetivo do Gerenciamento de Projetos é alcançar o sucesso da execução de projetos de maneira estruturada e transparente junto ao contratante. Considerando o atual cenário dinâmico, gerenciar projetos de forma efetiva é um dos grandes desafios nos tempos modernos. As mudanças em diversos aspectos da vida humana e do macroambiente estão ocorrendo cada vez mais rápido e considerar esses aspectos na elaboração de projetos é fundamental para a sua efetividade (Vieira, 2002).

Nesse sentido, uma proposta coesa de projeto, segundo Ortega (2010) e Fernandes (2015), deve considerar aspectos como data, prazo de validade, forma de pagamento, fatos e dados sobre a proponente, benefícios para a empresa contratante e a aplicação, abrangendo escopo e cronograma. Esses aspectos, segundos os autores, são imprescindíveis, pois transparecem conhecimento sobre a estrutura da contratante, os pontos chave a serem abordados e o conhecimento sobre as melhores práticas de gestão.

Prado (2002) e Papke-Shields, Beise e Quan (2010) indicam que um projeto é bemsucedido quando é concluído, respeitando prazos, custos, escopo e qualidade prédeterminados, não bastando apenas o alcance dos resultados e dos benefícios esperados. Kerzner (2011) abrange outros elementos para definir o sucesso de um projeto além dos já citados, incluindo as variáveis desempenho, aceitação do cliente/usuário e respeito à cultura corporativa.

Outros critérios são mencionados como sinalizadores de um projeto de sucesso, contudo, não há consenso quanto aos determinantes, já que variáveis internas e externas inesperadas podem afetar o ambiente organizacional e, consequentemente, o sucesso do projeto. Críticas à parte, as variáveis prazo, custo e qualidade ainda são amplamente tidas como a tríade fundamental dentre as métricas 
existentes para Gerenciamento de Projetos (Papke-Shields, Beise, \& Quan, 2010).

Para o sucesso da implantação de um projeto, Pinto e Sleven (1987) consideram o atendimento a quatro critérios - tempo, custo, eficácia e satisfação do cliente. Com base nesses critérios, foi formulado o conceito dos fatores críticos de sucesso (FCS) de um projeto que são “características, condições ou variáveis que podem ter um impacto significativo no sucesso de um projeto quando sustentados, mantidos e gerenciados apropriadamente" (Milosevic \& Patanakul, 2005, p. 183).

O uso da abordagem de FCS ajuda a identificar os fatores de maior impacto do projeto e implica em uma série de princípios que servem de suporte para um gerenciamento adequado (Milosevic \& Patanakul, 2005; Sanchez \& Robert, 2010). A literatura indica alguns dos principais fatores críticos de sucesso (FCS) para implementação eficiente de um projeto (Pinto \& Sleven; 1987; Rabechini, Carvalho, \& Laurindo, 2002; Milosevic \& Patanakul, 2005; Berssaneti, Carvalho, \& Muscat, 2016):

- Suporte gerencial: estímulo dos gestores envolvidos para adesão ao projeto;

- Planejamento: estabelecimento das atividades e forças-tarefa do projeto;

- Cliente consultor: comunicação;

- Questões de administração de pessoal: alocação de pessoal;
- Tarefas técnicas: disponibilidade e competência para acompanhar as tarefas técnicas;

- Aceite do cliente: "venda" do escopo do projeto;

- Monitoramento: oferta de feedback dos estágios do projeto;

- Comunicações: formação de rede que forneça informações no ambiente do projeto; e

- Gerência conciliadora: equipe intermediadora em possíveis crises que apareçam no projeto.

Endossando alguns desses fatores, em estudo com prefeituras de Santa Catarina, Link, Silva, Barichello e Dal Magro (2020) encontram evidências do impacto de alguns deles no sucesso dos projetos, dentre os quais, inovação, liderança, gestão da equipe, gestão de recursos, comunicação e partes interessadas. Já em estudo direcionado ao desempenho de Escritórios de Gerenciamento de Projetos, Oliveira e Martins (2020) e Oliveira, Cruz e Oliveira (2018), ao analisarem diferentes objetos de estudo, identificaram que os aspectos mais impactantes estão relacionados à estratégia, às operações e às pessoas.

Quanto ao impacto das pessoas no sucesso dos projetos, Nguyen (2019) aponta que aspectos relacionados ao comportamento da equipe são fatores críticos de sucesso de um projeto, tendo a ênfase no planejamento e na organização do projeto efeitos significativos na satisfação do cliente com a qualidade do projeto. Sinesilassie, Tabish e Jha (2017) 
também destacam aspectos relacionados às pessoas, indicando que conflito entre os membros da equipe, problemas na gestão de pessoas e falta de conhecimento do gerente de projeto impactam negativamente o desempenho do cronograma do projeto. Zhang, Yang, Liao e Chen (2020) relatam ainda que políticas de seleção, avaliação e incentivo, bem como fatores do ambiente de negócios, como cultura organizacional, tecnologia da informação e processos, afetam a capacidade de gerenciar projetos das organizações.

Independentemente dos FCS utilizados no escopo do projeto, para que o gerenciamento ocorra de maneira eficiente, as organizações devem ter um nível de maturidade conciso para a efetividade das ações. De acordo com Kerzner (2001), a maturidade em Gerenciamento de Projetos de uma empresa nada mais é que a medida de sua eficiência em concluir projetos e está dividida em cinco níveis: inicial; gerenciado (ações reativas ao projeto); definido (ações antecipadas ao projeto); quantitativamente gerenciado (indicadores quantificados para melhorias); e otimizado (melhoria contínua de processos).

Para Rabechini e Carvalho (2005), a maturidade para a aplicação do Gerenciamento de Projetos de maneira efetiva tem ocorrido nas organizações devido ao entendimento de os projetos serem a maneira mais efetiva para mudar uma situação complexa. Para Berssaneti, Carvalho e Muscat (2016), o conceito de maturidade em projetos está estreitamente ligado às possibilidades de sucesso/fracasso.
Esses autores demonstraram que as empresas classificadas como maduras apresentam desempenhos superiores em prazo, orçamento e requisitos comparadas àquelas classificadas como não maduras. Fernandes e Garcez (2019) também concluíram que há indicativos que a alta maturidade em Gerenciamento de Projetos pode contribuir para o alcance de vantagens competitivas.

Souza e Gomes (2015) citam que as organizações utilizam diversas ferramentas e modelos para medir seu grau de maturidade com o intuito de avaliar e aperfeiçoar a capacidade de gerenciar projetos. A década de 1990 marcou a expansão desses modelos, abordando os primeiros organizações ligadas à tecnologia de informação, como o SEI Capability Maturity Model (SW-CMM). Posteriormente, com base no PMBOK®, foram desenvolvidos outros modelos de maturidade em Gerenciamento de Projetos, como o Organizational Project Management Maturity Model (OPM3) e o Project Management Maturity Model (PMMM) (Berssaneti, Carvalho, \& Muscat, 2016).

É oportuno mencionar as críticas que são feitas em relação à teoria tradicional de Gerenciamento de Projetos, que envolvem aspectos como a burocracia e a rigidez das abordagens clássicas. Essas demandas resultaram na formulação de uma nova forma de abordagem, denominada Gerenciamento Ágil, ou Agile Project Management. A abordagem ágil de Gerenciamento de Projetos é baseada, principalmente, na flexibilidade, cujo objetivo é 
o de agregar valor ao produto de forma incremental. Sua principal diferença em relação à abordagem tradicional está nas técnicas e ferramentas empregadas e não nas ações de planejamento e controle, que apresentam características semelhantes entre as abordagens (Eder, Conforto, Amaral, \& Silva, 2015).

Para Angioni et al. (2006), as ferramentas ágeis são orientadas para o resultado do projeto e buscam adaptar o processo para absorver mudanças no escopo e funcionalidades no produto, diferentemente das abordagens tradicionais que, de acordo com Chin (2004), são estruturadas por processos com ênfase no planejamento detalhado.

$\mathrm{Na}$ visão de Mafakheri, Nasiri e Mousavi (2008), um projeto ágil deve considerar as seguintes dimensões: dinamismo (possíveis alterações e entregas parciais rápidas); comunicação (maior participação do cliente); tamanho da equipe (equipes mais enxutas); teste (capacidade de rever o processo com frequência); e conhecimento e habilidades dos desenvolvedores (membros da equipe com conhecimento necessário para executar e adaptar o projeto).

Embora as abordagens tradicional e ágil de Gerenciamento de Projetos tenham características distintas e pareçam antagônicas, há propostas de combinação entre ambas. A gestão híbrida de projetos, de acordo com Boehm e Turner (2005), trata da implementação da gestão ágil de projetos em ambientes tradicionais, identificando empresas que combinaram ambas as abordagens em um mesmo projeto. De acordo com Chin (2004) e Barlow, Giboney, Keith, Wilson e Schuetzler (2011), na abordagem híbrida, as tarefas do projeto são decompostas em módulos de forma mais independente possível, formando um mix ideal entre as abordagens tradicional e ágil que, por sua vez equilibra a necessidade de criatividade com a disciplina requerida para lançar e manter o sucesso dos produtos.

\section{Procedimentos metodológicos}

Ao considerar o objetivo desta pesquisa, que é compreender as particularidades e as necessidades das EJs em relação ao Gerenciamento de Projetos, bem como oferecer insights que possam contribuir com essas organizações, a sua classificação é considerada como exploratória, pois visa aumentar o conhecimento sobre determinada situação, promovendo o desenvolvimento de ideias sobre aquela realidade (Gil, 2002).

Para o alcance do objetivo proposto, a pesquisa foi realizada em duas etapas. A primeira, de abordagem qualitativa, buscou compreender determinadas situações e fatores do comportamento de um grupo social, não se apoiando, inicialmente, em dados numéricos com o intuito de compreender, de maneira subjetiva, o universo de significados, motivos, aspirações, crenças, valores e atitudes da unidade de análise (Minayo, 2001; Gerhardt \& Silveira, 2009).

Para isso, foi realizado um estudo de casos múltiplos com seis EJs como objeto de estudo, coletando informações relacionadas às 
experiências de mercado e acadêmicas para avaliar o nível de efetividade das práticas de Gerenciamento de Projetos. Foi escolhido o estudo de caso como a estratégia da primeira etapa da pesquisa porque ele objetiva "[...] compreender fenômenos sociais e psicológicos complexos, em que múltiplas variáveis intervêm" (Carneiro, 2018, p. 314). Além disso, esse tipo de estudo possibilita uma análise investigativa profunda no contexto real em que os objetos de pesquisa estão inseridos (Yin, 2001), bem como permite o levantamento e a organização dos dados, mantendo as características específicas unitárias das EJs estudadas (Goode \& Hatt, 1979).

A opção pela realização de casos múltiplos deriva da necessidade de coletar diferentes perspectivas em termos de práticas de Gerenciamento de Projetos por EJs, podendo este estudo ser classificado como estudo de casos múltiplos holístico, conforme apontam Yin (2001) e Campos, Cunha, Barbosa, Resende, \& Maia (2018), sendo cada EJ uma unidade de análise individual dentro de um estudo que abrange várias EJs, possibilitando comparação entre elas, tendo sido o procedimento metodológico replicado em todos os casos (Martins, 2008).

O critério de seleção das EJs participantes do estudo foi o nível de maturidade estabelecido pela Brasil Júnior. Foram estudadas EJs dos cinco níveis existentes, sendo os quatro primeiros níveis com uma empresa cada e o quinto nível, com duas empresas, possibilitando uma visão abrangente do universo de análise. A coleta de dados da primeira etapa foi realizada por meio de entrevistas com roteiro semiestruturado com média de uma hora de duração. Em seguida, os dados coletados foram transcritos e analisados conforme o método de análise de conteúdo proposto por Bardin (2009). A análise foi concentrada nas seguintes categorias, concebidas com base no referencial teórico utilizado:

a) Planejamento: busca compreender como é desenvolvida toda a etapa que antecede a execução do projeto;

b) Critérios e ferramentas: com o objetivo de identificar os critérios de alocação de recursos, de medição de sucesso, bem como as ferramentas (programas, softwares), os treinamentos e os documentos utilizados durante todo o projeto; e

c) Execução: busca entender como os projetos são gerenciados em seu desenvolvimento.

$\mathrm{Na}$ segunda etapa do estudo, foi realizada uma pesquisa quantitativa, já que a atenção era voltada ao coletivo, às características e aos fatores determinados a partir do grupo de EJs estudadas na etapa anterior (Mussi, Mussi, Assunção, \& Nunes, 2019). A survey via questionário foi o método de pesquisa escolhido para essa etapa do estudo, 
pois havia o interesse em gerar dados quantitativos de uma população, tendo sido utilizado, para tanto, um instrumento de pesquisa padronizado e previamente definido de modo a retratar a realidade atual das EJs (Freitas, Oliveira, Saccol, \& Moscarola, 2000).

As assertivas do questionário tiveram origem nos pontos mais discutidos nas entrevistas da primeira etapa, considerando os aspectos de maior relevância com o intuito de gerar resultados de forma objetiva em relação ao tema Gerenciamento de Projetos para as EJs. A divulgação do questionário foi realizada de forma online por meio de redes sociais - grupos nacionais do MEJ via redes sociais e grupo de mensagens rápidas de empresários juniores - e por e-mails direcionados aos Núcleos e Federações.

No questionário, os participantes inseriam seus dados descritivos - nome da EJ, universidade onde a EJ está inserida, estado de localização da Universidade, área de atuação da EJ e cursos que a compõem, função dos entrevistados e tempo de atuação na EJ. A segunda parte do questionário era constituída de 18 perguntas, sendo utilizada, em 14 delas, a escala Likert de cinco pontos (de 1 - discordo totalmente a 5 - concordo totalmente), além de questões com opções de múltipla escolha.
Para análise dos dados quantitativos, foi utilizado o software SPSS versão 20, sendo adotada a estatística descritiva e a análise de frequência. Os resultados das duas etapas da pesquisa são apresentados, analisados e discutidos no tópico seguinte.

\section{Análise e discussão dos resultados}

Como descrito nos Procedimentos Metodológicos, o estudo foi desenvolvido em duas etapas. Assim, esta seção de análise e discussão dos resultados também está organizada em duas etapas, com a apresentação e a análise dos resultados obtidos na etapa qualitativa e, em seguida, os dados obtidos na segunda etapa, ou seja, a quantitativa.

Inicialmente, foram analisados os dados da pesquisa qualitativa na qual foram realizadas entrevistas com seis EJs, considerando informações relacionadas às experiências de mercado e às acadêmicas com o intuito de entender o nível de efetividade de suas práticas de Gerenciamento de Projetos. A Tabela 1 apresenta as características das EJs entrevistadas. 
Tabela 1 - Características das empresas Juniores entrevistadas

\begin{tabular}{|c|c|c|c|c|c|}
\hline Empresa & Cidade/estado & Fundação & Membros & Área de atuação & Fat. Anual* \\
\hline Entrevistada 1 & Belo Horizonte (MG) & 1992 & 48 & Administração & $\mathrm{R} \$ 300.000,00$ \\
\hline Entrevistada 2 & Itajubá (MG) & 2014 & 28 & $\begin{array}{l}\text { Engenharia de Materiais, } \\
\text { Mecânica, Aeronáutica e } \\
\text { de Energia }\end{array}$ & $\mathrm{R} \$ 60.000,00$ \\
\hline Entrevistada 3 & Uberlândia (MG) & 2013 & 26 & Engenharia Química & $\mathrm{R} \$ 15.000,00$ \\
\hline Entrevistada 4 & São Paulo (SP) & 1992 & 62 & Administração & $\mathrm{R} \$ 500.000,00$ \\
\hline Entrevistada 5 & Itajubá (MG) & 1995 & 27 & Administração & $\mathrm{R} \$ 50.000,00$ \\
\hline Entrevistada 6 & Brasília (DF) & 1994 & 64 & Administração & $\mathrm{R} \$ 500.000,00$ \\
\hline
\end{tabular}

Nota: ${ }^{*}$ Fat. anual = Faturamento anual (informado pelos entrevistados com base nos dados de 2018).

Fonte: Dados da Pesquisa, 2020.

A seguir, são apresentados os resultados das entrevistas com os gestores das EJs em estudo segmentadas nas categorias concebidas na análise de conteúdo.

\subsubsection{Categoria 1: planejamento}

O escopo é o primeiro ponto a ser definido, uma vez que o cronograma, geralmente, leva em consideração o tempo de duração de cada etapa do projeto. Em relação à forma que as EJs entrevistadas determinam o escopo do projeto, as EJs 1, 4 e 5 ressaltam a importância de realizar previamente um diagnóstico efetivo como forma de compreender a real necessidade do cliente para a construção de um escopo adaptado a ele. A Entrevistada 5 destaca que "É, pela demanda do cliente, pelo diagnóstico que foi feito".

As EJs 2, 3 e 6 afirmam ter algumas atividades do escopo já padronizadas em seu portfólio, no entanto, reconhecem a relevância de personalizar algumas atividades de acordo com a necessidade do cliente. As empresas 2, 3 e 6 seguem estruturas de escopo do projeto já existentes, possivelmente, considerando as limitações e as experiências dos membros e por serem menos susceptíveis a erros, bem como por ser uma aplicação já consolidada, mas abertas a possíveis alterações de acordo com a demanda.

"Então, o escopo do projeto, ele é definido quando o analista, ele traz essas necessidades do cliente. [...] o gerente, ele capta todas essas informações trazidas por negócios, pela área de negócios, e ele formula, a partir daí a solução que seja adequada com as necessidades do cliente, e aí o escopo é definido. Claro que a gente já tem algumas soluções já padronizadas no nosso cardápio, assim, né, no nosso portfólio, mas, dependendo da necessidade do cliente, você pode propor umas soluções [...] como a gente costuma chamar de estudo especial [...] tem etapas de uma outra solução ou alguma coisa muito mais personalizada" (Entrevistada 6).

A tratativa apresentada pela maioria das EJs, salientando a importância do diagnóstico e da definição do escopo, está alinhada aos achados de Kiran \& Reddy (2019), que citam a má definição de requisitos e a alocação inadequada de recursos como fatores que levam ao insucesso de projetos de implementação de 
sistemas ERP em pequenas empresas. Esses autores destacam ainda a importância de conhecer as necessidades da organização para realização dos projetos.

$\mathrm{Na}$ elaboração do cronograma, a maioria das EJs utiliza o MS-Project ${ }^{\circledR}$, contudo, os critérios para definir a duração de cada etapa podem variar. Na EJ1, a duração de cada etapa varia de acordo com o projeto, considerando a necessidade do cliente. As EJs 3, 4, 5 e 6 consideram a gestão do conhecimento como um ponto-chave na definição de um cronograma assertivo, ou seja, a gestão é baseada em estimativas de acordo com o suporte de pessoas capacitadas e, a partir do momento que adquire experiência, fundamenta-se sua assertividade, como demonstrado no estudo de McClory e Ashraf Labib (2017), que evidencia a importância da gestão do conhecimento e a aprendizagem por meio dos projetos.

Todas as EJs entrevistadas consideram os seguintes fatores no orçamento: valor da hora de trabalho; número de consultores alocados; tempo de duração; e custos diversos envolvidos como deslocamento, materiais, entre outros. Além desses, as EJs 2 e 4 consideram também a situação específica do momento em que a capacidade produtiva, a estratégia da empresa e o faturamento anual esperado são pontos que influenciam no valor do projeto. Nesse sentido, a Entrevistada 2 cita: "resumindo, a gente coloca tudo no Project, manda pro financeiro, financeiro baixa aquele Project, vai analisar todos os gastos que têm nele, o homem-hora e tudo mais e daí, a partir disso, eles colocam o insumo numa planilha que eles têm. Eles vão ajustando a precificação [...] Como que tá a situação da empresa agora, se tá todo mundo com projeto ou se a gente tá querendo pegar o projeto, aqueles índices que normalmente a maioria das EJs tem, né, pra fazer o balanceamento, assim, da precificação" (Entrevistada 2).

A EJ1 adapta o valor da hora de trabalho à realidade do cliente, considerando sua dimensão de modo que, quanto maior a empresa atendida, maior o valor da hora de trabalho, considerando os recursos técnicos empregados. Como diz a Entrevistado 1: “A gente tem o preço médio da nossa hora e a gente precifica baseado nesse preço. Às vezes, de acordo com a realidade do cliente, a gente põe a hora um pouco abaixo, porque a gente sabe da disponibilidade dele que é mais baixa".

De maneira geral, foi verificado que, em todas as EJs entrevistadas, a proposta comercial é composta basicamente pelo escopo, cronograma e orçamento do projeto, elementos esses mencionados por Ortega (2010), que ainda sugere incluir os benefícios para a empresa contratante, que é algo não mencionado pelos entrevistados. A proposta é elaborada após agendamento da reunião de diagnóstico com o cliente com base nas informações captadas. 


\subsubsection{Categoria 2: critérios e ferramentas}

Todas as EJs consideram a satisfação do cliente para mensurar o sucesso de um projeto, seja por feedback direto ou por coleta do NPS (Net Promoter Score), que é uma ferramenta para medir a satisfação dos clientes. Contudo, os entrevistados acreditam que essa ferramenta, sozinha, não é suficiente e começaram, então, a estabelecer indicadores adaptados a cada projeto, mensurando a sua efetividade durante a execução, imediatamente após e alguns meses após realizado o serviço.

Em relação à alocação da equipe do projeto, as EJs, de maneira geral, se baseiam em critérios como: conhecimento técnico; interesse pessoal; competências; disponibilidade; entre outros. Para a definição do gerente do projeto, a EJ1 considera, além do conhecimento técnico e da experiência, o relacionamento com os consultores e o seu perfil de gerenciamento. Para alocação dos consultores, a empresa cita a importância de selecionar projetos mais curtos para aquelas pessoas que pretendem sair em breve da EJ de forma que possam executar o projeto enquanto permanecerem na empresa. Nesse sentido, esclarece a Entrevistada 1:

\begin{abstract}
"a gente também pondera a questão do conhecimento técnico que a pessoa tem $e$, às vezes, por exemplo, a gente alocou ontem uma menina que ela já tá há muito tempo na empresa e a gente não sabe se ela vai sair ou não [...], e a gente priorizou ela pra alocar num projeto curto. Se ela decidisse sair, ela conseguia executar o projeto e sair. A gente poderia alocar ela em um projeto de 65 dias [...], a gente alocou ela em um projeto de 23, e a gente consegue ter uma margem maior pra, tipo, se ela quiser sair, ela está executando um projeto menor que ela conseguia executar, finalizar $e$ sair, não tem nenhuma perda de conhecimento no projeto. A gente considera muita coisa, mas basicamente o interesse do consultor no projeto e o conhecimento técnico" (Entrevistada 1).
\end{abstract}

As EJ2 e EJ5 mantêm uma estrutura de gerentes de projetos fixos com o propósito de formá-los como especialistas em gerenciamento. As EJ3 e EJ6 demonstram falta de critérios bem definidos para a alocação dos membros nos projetos, mas consideram que todos devem participar de, pelo menos, um projeto independente da área com o objetivo de agregar conhecimento de maneira geral entre seus membros. O PMI (2017) reconhece a importância das pessoas, ressaltando que habilidades interpessoais colaboram para o sucesso de projetos. A alocação de pessoal é um dos principais FCS, que é designar pessoas que tenham capacitação e afinidade com o projeto, otimizando as chances de alcançar os objetivos pré-estabelecidos (Pinto \& Sleven, 1987; Rabechini, Carvalho, \& Laurindo, 2002). Da mesma forma, Zhang et al. (2020), Nguyen (2019) e Sinesilassie, Tabish \& Jha (2017) apresentam diferentes aspectos relacionados à 
gestão de pessoas como fatores críticos para o sucesso de um projeto e consequente satisfação do cliente.

Sobre as ferramentas, técnicas e softwares utilizados para o planejamento e execução do projeto, todas citaram o PMBOK®, a abordagem tradicional de Gerenciamento de Projetos e o software MSProject ${ }^{\circledR}$. Na execução dos projetos, são utilizados modelos como o Waterfall, gráfico de Gantt e o EAP, sendo operacionalizados por meio do framework Scrum. Na EJ3, também foram citados a ferramenta Trello ${ }^{\circledR}$ e, de forma secundária, os sistemas colaborativos de armazenamento de dados nas nuvens para armazenamento, não se atentando à abordagem. Já a EJ6, além de utilizar o MS-Project ${ }^{\circledR}$ para a elaboração do cronograma, adota o Canvas ${ }^{\circledR}$ para o planejamento do projeto, além de algumas ferramentas elaboradas pela própria empresa. As empresas optam pelo uso da abordagem tradicional por ser esse um método já consolidado e, assim, menos suscetível a erros, o que confere maior segurança aos membros do projeto que ainda estão em processo de aprendizado (Eder et al., 2015; Freitas \& Paula, 2016). A ausência de uma sistemática de Gerenciamento de Projetos é apontada por Aranyossya, Blaskovicsa e Horváth (2018) como um possível fator de insucesso de projetos em determinados contextos.

Quanto à capacitação e aos treinamentos em Gerenciamento de Projetos, as EJ1, EJ3, EJ5 e EJ6 trabalham com treinamentos que abordam a área de gestão, ferramentas, estimativa de custos, entre outros, acontecendo tais capacitações ocasionalmente, ou mais especificamente, quando julgam necessário. A EJ3 busca treinamentos externos e cursos online para os membros participarem, sendo esses treinamentos internos ministrados somente quando há membros novos e projetos em desenvolvimento. Nesse sentido, explica a Entrevistada 3:

\begin{abstract}
"Então, quanto à capacitação, externamente, a gente tá sempre procurando né, algum evento que vai ter, algum congresso [...]. Quanto a essas capacitações externas, a gente tá sempre procurando assim... Participar, quando acontece em Uberlândia né, no sábado e tal. É... Agora, quanto à capacitação interna, geralmente, os Diretores é, costumam fornecer, montar uma capacitação, assim, principalmente, quando tem membros novos [...]" (Entrevistada $3)$.
\end{abstract}

As EJ2 e EJ4 optam por ministrar internamente dois tipos de capacitação: o primeiro deles ocorre apenas uma vez por ano, que é quando os trainees ingressam, sendo apresentada uma base geral sobre Gerenciamento de Projetos. Já o segundo treinamento é mais específico e focado em membros a serem designados para a gerência de projetos. Sobre esse aspecto, a Entrevistada 4 destaca: 
“A gente dá internamente, o Diretor de Projetos dá dois treinamentos. Um que é mais superficial, que é quando os membros acabam de entrar na empresa, que fala um pouco mais sobre planejamento, ou explica o escopo do projeto, EAP, esse tipo de coisa, só pra dar uma visão mais geral, é, sobre gerenciamento e um treinamento pra gerentes que a gente dá também. Aí, é uma coisa mais aprofundada, a gente discute sobre várias metodologias de planejamento, desde Scrum, PDCA, Design Thinking, Six Sigma, a gente pega várias práticas de Gerenciamento de Projetos que podem ser utilizadas pelo gerente [...] Tem esses dois treinamentos, um pouco mais superficial, pros trainees quando acabam de entrar, e um pra quando as pessoas tão fazendo treinamento pra virar gerentes, que é mais aprofundado. $O$ de gerentes é duas vezes, o de trainee é uma vez. A gente só tem entrada uma vez por ano na empresa, de membros" (Entrevistada 4).

Pant e Baroudi (2008) destacam a importância do treinamento para o sucesso no Gerenciamento de Projetos, salientando a sua relevância no contexto da formação profissional universitária, incluindo o desenvolvimento de habilidades consideradas humanas, que são tidas como soft, cada vez mais requeridas no contexto real das organizações. Para Rabechini, Carvalho e Laurindo (2002), as equipes de projetos alcançam alto desempenho de execução e acompanham a movimentação do mercado em que estão inseridas somente por meio de investimentos constantes em treinamento e desenvolvimento. Os treinamentos viabilizam a compreensão de um novo sistema, operação de novas plataformas, entendimento do comportamento do mercado, entre outros pontos.

\subsubsection{Categoria 3: execução}

Em relação ao gerenciamento do escopo do projeto, as EJ1, EJ4 e EJ6 destacam a necessidade de acompanhar o escopo com frequência semanal, incluindo a revisão dos horários limites de entrega das etapas de acordo com o andamento do serviço. Nas EJ1, EJ3 e EJ5, por exemplo, as etapas amplas são divididas em micro etapas pelo gerente de projetos para que os consultores consigam enxergar os resultados de maneira mais minuciosa e formular ações, bem como estipular prazo para a próxima etapa, sendo todos esses aspectos debatidos na reunião semanal. Nesse sentido, a Entrevistada 3 destaca:

\footnotetext{
"Então, a gente discrimina todas essas atividades, a gente faz o cronograma e, aí, vai do GP ele fazer esse gerenciamento, né? Ele que tem que cobrar as atividades dentro do prazo, ter esse engajamento, ter esse feeling de ter que fazer todas as atividades no prazo, né? Aí a gente tem também o sistema de gamification, que tem os pontos no final do mês (Entrevistada 3).
}

A maioria das EJs entrevistadas utiliza o MS-Project ${ }^{\circledR}$ para gerenciar o cronograma, que é preenchido pelos gerentes de projetos conforme o andamento do projeto. Algumas utilizam também o Trello®, como a EJ6, que afirma que o perfil de cada gerente ou líder influencia na sua forma de gerenciamento, sendo as metas controladas de acordo com sua determinação. As falas seguintes exemplificam essa situação: “A gente, normalmente, usa o Trello, que é uma ferramenta também pra 
acompanhamento do cronograma, mas cobrança de metas, a elaboração de metas semanais, isso fica a critério de cada líder" (Entrevistada 6).

"Pra gerenciar não só esses dois. Pra fazer todo o gerenciamento e o outro pra fazer mais o gerenciamento da comunicação e tudo mais, pro resto da equipe saber, né, o que tá sendo executado, mas, normalmente, só esses dois. Mas a gente também tem uma planilha de gerenciamento de riscos que a gente trabalha em paralelo com o Project, a planilha de gerenciamento de riscos e o Trello (Entrevistada 2).

Todas as EJs entrevistadas controlam os custos dos projetos com base no planejamento desenvolvido na etapa de precificação. A ferramenta de controle varia entre MS-Project ${ }^{\circledR}$ e o MS-Excel®. A EJ5 cita que a necessidade de melhoria no gerenciamento de custos, principalmente, em relação às horas trabalhadas, em que, esporadicamente, ocorrem discrepâncias. O trecho seguinte demonstra essa necessidade.

"É... Todo custo a pessoa tem que pegar nota fiscal, né? Vamos supor, quando tem algum gasto no projeto, $e$ mandar pro gerente financeiro que faz o controle naquela planilha de balanço financeiro, é uma coisa que a gente precisa melhorar também, as horas previstas, as horas trabalhadas. A gente precisa começar a gerenciar melhor, porque a gente cobra por hora, mas a gente não consegue gerenciar tão bem as horas que a gente trabalha" (Entrevistada 5).

Em relação a controle, de acordo com Kerzner (2011), esse é um dos fundamentos elementares do Gerenciamento de Projetos, juntamente com o planejamento, a organização e a direção. Sem ele, não é possível atingir um objetivo e concluir metas e objetivos específicos. Para Prado (2002) e Papke-Shields, Beise e Quan (2010), um projeto bem-sucedido deve ser concluído, respeitando prazos, custos, escopo e qualidade pré-determinados e, para isso, ter medidas e ferramentas de controle efetivas é fundamental. As empresas em estudo demonstraram trabalhar o controle de forma efetiva, podendo serem classificadas na segunda categoria de práticas de monitoramento de Rabechini, Carvalho e Laurindo (2002), referente às empresas cuja prática do monitoramento é ainda incipiente (procedimentos em estágios iniciais e em evolução) e cujo sistema começa a utilizar práticas informatizadas.

Em relação à qualidade dos projetos, o controle da EJ5 é realizado por meio de feedbacks coletados junto ao cliente. Williams, Ashill, Naumann e Jackson (2015) destacam que a satisfação do cliente e a qualidade do relacionamento com ele são importantes critérios na avaliação do sucesso de um projeto. Por outro lado, a EJ4 faz esse controle de maneira formal por meio de três auditorias que são realizadas pelos diretores: uma, no início do projeto, com o objetivo de verificar se os prérequisitos para iniciar o projeto foram cumpridos; outra, na metade, para coletar o NPS parcial, dar feedback para o gerente e, se necessário, traçar algum plano de ação em conjunto com ele; e a última, ao final do projeto, para conferir toda a documentação. As ações das empresas, principalmente da EJ4, estão 
alinhadas ao posicionamento de Rabechini e Carvalho (2005), que citam o aperfeiçoamento da capacidade para gerenciar projetos por meio da melhoria do controle, pautado em indicadores como eficácia, prazo, custo, satisfação do cliente e riscos associados. Essa situação pode ser evidenciada na fala da Entrevistada 4:

\begin{abstract}
"A qualidade é controlada com uma auditoria, que é feita pelos Diretores. A gente faz uma auditoria no início do projeto, pra ver se [...] todos os prérequisitos pra iniciar o projeto foram completados. Então, se já teve reunião de alinhamento com o cliente, se teve, se o planejamento foi montado, [...] uma auditoria inicial, uma auditoria na metade do projeto, que a gente também faz a coleta do que a gente chama de NPS parcial. Chega na metade do projeto, eu ligo pro cliente, coleto a satisfação parcial dele e, aí, eu junto com o gerente e traço algum plano de ação ou passo esse feedback pra ele, positivo ou negativo. $E$, depois que o projeto acaba, também a gente faz essa auditoria pra ver se toda a documentação foi entregue, [...] Por exemplo, se todos os feedbacks foram passados, se o case de documentação interna já foi realizado [...] Coisas assim. Então, basicamente, são realizadas três auditorias, uma no início, uma na metade e uma no final do projeto, sendo que a do meio também inclui um contato com o cliente, a do início e do final é só o Diretor de Projetos com o gerente" (Entrevistada 4).
\end{abstract}

Sobre a participação do diretor de projetos, as EJ1 e EJ5 prezam pela autonomia do gerente, pois acreditam que ele é responsável pelas decisões em primeiro momento. Já nas EJ2, EJ3, EJ4 e EJ6, os diretores têm participação mais ativa, com feedbacks enviados diariamente, seja via reuniões, e-mails ou por aplicativo de mensagens. A participação efetiva do diretor de projetos é um dos fatores críticos para o sucesso do projeto, como citado por Pinto e Sleven (1987), Rabechini, Carvalho e Laurindo (2002) e Berssaneti, Carvalho e Muscat (2016).

Analisando a execução das empresas em estudo, a maioria atua conforme os pressupostos de PMI (2017). As EJs gerenciam seu escopo, procurando garantir que o projeto inclua apenas as etapas de trabalho necessárias e indispensáveis, buscando também assegurar o término do projeto dentro do prazo, conforme orçamento previamente estipulado.

\subsection{Etapa quantitativa}

Nessa etapa, são apresentados os resultados da pesquisa quantitativa realizada por meio da aplicação de uma survey com 100 empresários juniores. As assertivas do questionário tiveram origem nos pontos mais discutidos nas entrevistas, considerando aqueles de maior relevância com o intuito de gerar resultados de forma objetiva em relação ao tema Gerenciamento de Projetos para as EJs. É interessante ressaltar a representatividade das EJs abordadas nessa etapa, visto que, atualmente, existem 805 EJs confederadas (Brasil Júnior, 2020a). Dessa forma, é possível considerar que $12,42 \%$ foram abrangidas neste estudo.

Foram identificadas EJs de 14 estados diferentes, contando com universidades federais, estaduais ou particulares. Minas Gerais foi o estado mais representado, com 65 
empresas, seguido do Paraná (nove) e São Paulo (sete), perfazendo, nos demais estados, um total de 19 empresas. No campo de atuação, foram identificadas oito áreas distintas, representando as "Engenharias" o maior número, abrangendo 56 empresas, seguidas de "Gestão Empresarial", com 24, e as demais áreas (Ciências Agrárias, Ciências da Saúde, Ciências Naturais, Ciências Sociais e Humanas e Direito), com 20 empresas. Analisando as instituições das quais as empresas são provenientes, a Universidade Federal de Uberlândia (UFU) somou o maior número de participantes, totalizando $34 \mathrm{EJ}$ s, seguida da Universidade Federal de Minas Gerais (UFMG), com sete, Universidade Federal do Triângulo Mineiro (UFTM), com seis empresas, contando as demais instituições com 53 empresas. A Tabela 2 apresenta os dados sobre as 100 EJs participantes da survey.

Tabela 2 Estado, instituição de ensino e área de atuação das EJs dos 100 participantes da

\begin{tabular}{|c|c|c|c|}
\hline survey & & & Continua \\
\hline Estado & IES & Área de atuação & Frequência \\
\hline Bahia & UFBA & Demais áreas & 1 \\
\hline Bahia & UFBA & Gestão Empresarial & 1 \\
\hline Ceará & UFC & Demais áreas & 1 \\
\hline Distrito Federal & $\mathrm{UnB}$ & Engenharias & 1 \\
\hline Goiás & UFG & Demais áreas & 1 \\
\hline Minas Gerais & IFSULDEMINAS & Gestão Empresarial & 1 \\
\hline Minas Gerais & UFJF & Demais áreas & 1 \\
\hline Minas Gerais & UFJF & Engenharias & 3 \\
\hline Minas Gerais & UFJF & Gestão Empresarial & 1 \\
\hline Minas Gerais & UFLA & Demais áreas & 1 \\
\hline Minas Gerais & UFLA & Engenharias & 2 \\
\hline Minas Gerais & UFLA & Gestão Empresarial & 1 \\
\hline Minas Gerais & UFMG & Demais áreas & 1 \\
\hline Minas Gerais & UFMG & Engenharias & 3 \\
\hline Minas Gerais & UFMG & Gestão Empresarial & 3 \\
\hline Minas Gerais & UFOP & Engenharias & 1 \\
\hline Minas Gerais & UFTM & Engenharias & 6 \\
\hline Minas Gerais & UFU & Demais áreas & 7 \\
\hline Minas Gerais & UFU & Engenharias & 15 \\
\hline Minas Gerais & UFU & Gestão Empresarial & 12 \\
\hline Minas Gerais & UFV & Demais áreas & 3 \\
\hline Minas Gerais & UFV & Engenharias & 1 \\
\hline Minas Gerais & UFVJM & Demais áreas & 1 \\
\hline Minas Gerais & UNIFEI & Engenharias & 2 \\
\hline Pará & UNIFESSPA & Engenharias & 1 \\
\hline Paraíba & UFPB & Engenharias & 2 \\
\hline Pernambuco & UFPE & Engenharias & 1 \\
\hline
\end{tabular}




\begin{tabular}{|c|c|c|c|}
\hline Estado & IES & Área de atuação & Frequência \\
\hline Paraná & UEL & Gestão Empresarial & 1 \\
\hline Paraná & UEM & Engenharias & 3 \\
\hline Paraná & UFPR & Demais áreas & 1 \\
\hline Paraná & UFPR & Engenharias & 2 \\
\hline Paraná & UTFPR & Engenharias & 2 \\
\hline Rio de Janeiro & UERJ & Engenharias & 1 \\
\hline Rio de Janeiro & UFF & Gestão Empresarial & 1 \\
\hline Rio de Janeiro & UFRJ & Engenharias & 1 \\
\hline Rio de Janeiro & UFRJ & Gestão Empresarial & 1 \\
\hline Rio Grande do Norte & UFERSA & Engenharias & 1 \\
\hline Rio Grande do Sul & UFPel & Engenharias & 1 \\
\hline Rio Grande do Sul & UFSM & Engenharias & 1 \\
\hline Rio Grande do Sul & UFRGS & Gestão Empresarial & 1 \\
\hline Santa Catarina & UFSC & Engenharias & 1 \\
\hline Santa Catarina & UFSC & Gestão Empresarial & 1 \\
\hline São Paulo & UFSCar & Engenharias & 2 \\
\hline São Paulo & UNESP & Demais áreas & 1 \\
\hline São Paulo & UNIFESP & Engenharias & 1 \\
\hline São Paulo & USP & Demais áreas & 2 \\
\hline São Paulo & USP & Engenharias & 1 \\
\hline
\end{tabular}

Fonte: Dados da Pesquisa, 2020.

Analisando, inicialmente, as médias das variáveis concebidas na fase qualitativa, foram identificadas 14 variáveis, as quais foram mensuradas por meio da escala Likert de cinco pontos, apresentadas na Tabela 3 em ordem decrescente.

Tabela 3 Média e desvio padrão das variáveis

\begin{tabular}{|c|c|c|c|}
\hline Código & Variável & Média & $\begin{array}{l}\text { Desvio } \\
\text { Padrão }\end{array}$ \\
\hline 04 & $\begin{array}{l}\text { Uma boa proposta comercial deve conter os benefícios e resultados que o projeto } \\
\text { pode trazer para o cliente }\end{array}$ & 4,65 & 0,62563 \\
\hline 03 & Uma boa proposta comercial deve conter o orçamento do projeto & 4,55 & 0,65713 \\
\hline 07 & $\begin{array}{l}\text { A realização de um diagnóstico efetivo é indispensável na construção do escopo } \\
\text { do projeto }\end{array}$ & 4,47 & 0,65836 \\
\hline 08 & A gestão do conhecimento é importante na definição do escopo do projeto & 4,35 & 0,77035 \\
\hline 13 & $\begin{array}{l}\text { Os treinamentos e capacitações para os membros sobre Gerenciamento de } \\
\text { Projetos são importantes para o aperfeiçoamento da execução dos projetos }\end{array}$ & 4,35 & 0,80873 \\
\hline 01 & Uma boa proposta comercial deve conter o escopo do projeto & 4,22 & 0,9383 \\
\hline 09 & A gestão do conhecimento é importante na definição do cronograma do projeto & 4,18 & 0,88054 \\
\hline 12 & $\begin{array}{l}\text { A assinatura de um termo que determina a conclusão do projeto é importante } \\
\text { para a minha EJ }\end{array}$ & 4,02 & 1,02474 \\
\hline 02 & Uma boa proposta comercial deve conter o cronograma do projeto & 3,97 & 1,12326 \\
\hline 11 & $\begin{array}{l}\text { A assinatura de um termo que determina a abertura do projeto é importante para } \\
\text { a minha EJ }\end{array}$ & 3,91 & 1,14676 \\
\hline
\end{tabular}




\begin{tabular}{|c|c|c|c|}
\hline & & & Conclusão \\
\hline Código & Variável & Média & $\begin{array}{l}\text { Desvio } \\
\text { Padrão }\end{array}$ \\
\hline 14 & $\begin{array}{l}\text { O Gerenciamento do Projeto envolve revisão do planejamento e novas metas } \\
\text { com determinada frequência }\end{array}$ & 3,88 & 0,83218 \\
\hline 05 & $\begin{array}{l}\text { A proposta deve ser desenvolvida por um membro responsável pelo atendimento } \\
\text { ao cliente }\end{array}$ & 3,62 & 1,02277 \\
\hline 06 & $\begin{array}{l}\text { A proposta deve ser desenvolvida pelo membro que, possivelmente, será o } \\
\text { gerente do projeto }\end{array}$ & 3,51 & 1,08707 \\
\hline 10 & $\begin{array}{l}\text { A coleta do NPS (Net Promoter Score) é eficiente para mensurar o sucesso de } \\
\text { um projeto }\end{array}$ & 3,51 & 0,9898 \\
\hline
\end{tabular}

Fonte: Dados da Pesquisa, 2020.

A variável com maior média foi "Uma

conforme a demanda da organização

boa proposta comercial deve conter os

benefícios e resultados que o projeto pode trazer

(Rabechini, Carvalho, \& Laurindo, 2002).

Outras variáveis mencionadas com para o cliente", destacando que as EJs entendem que as propostas devem contar com os pontos positivos que podem ser proporcionados à organização que contrata o trabalho da EJ, até mesmo como um atrativo para que a contratação possa ser efetivada. Nesse sentido, Ortega (2010) e Fernandes (2015) citam que, entre as informações presentes na proposta, os possíveis resultados do projeto para a empresa contratante devem estar inclusos como forma de materializar os benefícios advindos do investimento.

Em segundo lugar, foi mencionada a variável "Uma boa proposta comercial deve conter o orçamento do projeto", na qual está detalhado o investimento que será realizado pela empresa contratante (Ortega, 2010), seguida da variável "A realização de um diagnóstico efetivo é indispensável na construção do escopo do projeto", que destaca a importância do diagnóstico, o qual deve representar a situação real e atual da organização (Santos, Francischetti, Sacomano, Padoveze, \& Spers, 2013), pois é a partir desse diagnóstico que serão estruturadas todas as diretrizes a serem seguidas pela equipe 
Por fim, foi questionado aos entrevistados quais fatores são considerados pelas EJs para a elaboração do projeto, para a alocação de gerentes de projetos e consultores para determinado projeto e qual a abordagem utilizada no Gerenciamento de Projetos.

Tabela 4 - Fatores considerados para Elaboração do Orçamento do Projeto

\begin{tabular}{lc}
\hline \multicolumn{1}{c}{ Fator } & Citações \\
\hline Custos envolvidos & 90 \\
Tempo de duração & 81 \\
Valor da hora de trabalho & 74 \\
Número de membros alocados & 68 \\
Disponibilidade de pagamento do cliente & 68 \\
Complexidade do projeto & 8 \\
\hline
\end{tabular}

Fonte: Dados da Pesquisa, 2020.

Inicialmente, foram avaliados os fatores envolvidos para a elaboração do projeto. Conforme apresentado na Tabela 4 , o fator mais mencionado foi "Custos envolvidos", que trata de questões ligadas ao orçamento no intuito de entregar o melhor serviço ao cliente, garantindo também uma margem justa à EJ que desenvolve o trabalho. Em seguida, foram mencionados também, em boa quantidade, os seguintes aspectos: o tempo de duração do projeto, visto que entregar ao cliente um diagnóstico no menor tempo possível dentro das condições disponíveis é um ponto-chave para o sucesso do projeto; o valor da hora de trabalho, que também está envolvido no orçamento. $\mathrm{Na}$ mesma quantidade, estão: "Número de membros alocados", observando a mão de obra conforme a demanda necessária; e "Disponibilidade de pagamento do cliente". O fator "Complexidade do projeto" foi pouco mencionado entre os entrevistados.

Tabela 5 - Critérios para Alocação de Gerentes de Projetos

\begin{tabular}{lc}
\hline \multicolumn{1}{c}{ Fator } & Citações \\
\hline Disponibilidade & 79 \\
Conhecimento técnico & 57 \\
Competências pessoais & 54 \\
Interesse do membro naquele projeto/área & 53 \\
Experiências prévias & 40 \\
Não há critérios bem definidos & 10 \\
\hline
\end{tabular}

Fonte: Dados das Pesquisa, 2020.

$\mathrm{Na}$ Tabela 5, foram apresentados os principais critérios apontados para a alocação do gerente de projetos em determinado projeto. $\mathrm{O}$ primeiro critério mencionado foi a "Disponibilidade", que também foi citada na fase qualitativa da pesquisa e diz respeito aos gerentes serem destacados para determinado projeto, considerando, principalmente, sua disposição. Em seguida, foi mencionado "Conhecimento técnico", aspecto também 
mencionado com destaque na fase qualitativa, referente aos gerentes serem destacados de acordo com as competências demandadas no projeto. As "Competências pessoais" e "Interesse do membro pelo projeto na área" também foram critérios citados, visto que o engajamento do gerente com o projeto é um fator importante no desenvolvimento de atividades. Os aspectos "Experiências prévias" e "Não há critérios bem definidos" foram mencionados em menor intensidade.

Tabela 6 - Critérios para Alocação de Consultores

\begin{tabular}{lc}
\hline \multicolumn{1}{c}{ Fator } & Citações \\
\hline Disponibilidade & 76 \\
Interesse do membro naquele projeto/área & 56 \\
Conhecimento técnico & 42 \\
Competências pessoais & 41 \\
Experiências prévias & 34 \\
Não há critérios bem definidos & 14 \\
\hline
\end{tabular}

Fonte: Dados das Pesquisa, 2020.

Assim como na alocação de gerentes, o fator mais citado no que diz respeito à alocação de consultores foi "Disponibilidade", seguido do "Interesse do membro naquele projeto/área", o que mostra que o engajamento pessoal do consultor é o principal ponto para sua alocação no projeto, conforme apontam os entrevistados
(Tabela 6). O "Conhecimento Técnico" e as "Competências pessoais" foram mencionados logo em seguida e consideram a preparação e o conhecimento técnico do consultor para a atuação no projeto. "Experiências prévias" e "Não há critérios bem definidos" também foram mencionados, mas com menor intensidade.

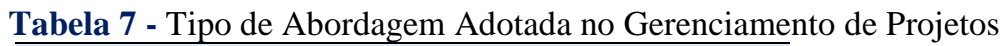

\begin{tabular}{cc}
\hline Abordagens & Citações \\
\hline Tradicional & 53 \\
Ágil & 22 \\
Híbrida & 22 \\
Outra & 3 \\
\hline
\end{tabular}

Fonte: Dados das Pesquisa, 2020.

Por fim, a Tabela 7 apresenta as abordagens utilizadas pelas EJs nas quais os entrevistados estão alocados. A abordagem "Tradicional" foi amplamente a mais mencionada, estando presente em 53\% das EJs, o que evidencia que elas ainda seguem padrões clássicos no Gerenciamento de Projetos devido a seus membros estarem em desenvolvimento no meio acadêmico e por essa abordagem oferecer maior segurança de aprendizado, tendo em vista a sua operacionalização já ser amplamente consolidada. As abordagens "Ágil” e "Híbrida" foram mencionadas na mesma quantidade, somando 44\%, o que mostra as EJs abertas para adotar novas abordagens, preparando seus membros para melhor lidar 
com novos arranjos de Gerenciamento de Projetos.

Esses resultados são corroborados por Freitas e Paula (2016), que citam a opção por estruturas tradicionais que considerem as limitações e as experiências dos membros em aprendizado, visto que essa abordagem é menos susceptível a erros por já serem consolidadas. Contudo, as autoras citam a necessidade de mudanças e estruturação de novos processos, o que foi constatado por meio da boa representatividade das abordagens ágil e híbrida, que também são utilizadas pelas EJs brasileiras. As EJs pautam essa mudança, buscando a flexibilidade de estrutura, a agregação de valor ao produto oferecido e a adaptação de processos para absorver mudanças no escopo e funcionalidades, bem como para acomodar o projeto de acordo com a demanda do cliente com maior flexibilidade (Angioni et al., 2006; Eder et al., 2015).

\section{Considerações finais}

Este artigo visou compreender as particularidades e as necessidades das EJs em relação ao Gerenciamento de Projetos e oferecer insights que possam contribuir com essas organizações que tanto agregam ao cenário educacional brasileiro. É possível perceber que as EJs apresentam diferentes necessidades em relação a outras organizações e, além disso, é factível afirmar que há particularidades entre as próprias EJs que variam em decorrência dos tipos de projetos que executam, da área em que atuam, da complexidade dos projetos, dos recursos disponíveis, dentre outros fatores.

De acordo com os resultados, é fundamental que, para guiar o projeto, haja um planejamento inicial, com escopo e cronograma definidos, mas tal planejamento deve ser passível de revisão, como alterações no escopo e no cronograma planejados inicialmente, caso necessário. A importância de os clientes terem uma participação mais ativa nos projetos, no sentido de acompanhar o seu andamento e validar as entregas para que as expectativas permaneçam sempre alinhadas, também foi perceptível. Para que o projeto tenha início com as expectativas alinhadas, o diagnóstico deve ser realizado de maneira bem estruturada, visando compreender a real necessidade do cliente, levantando questões abrangendo as diversas áreas da empresa e buscando identificar o problema raiz do cliente e onde a EJ deve atuar.

Como limitação do estudo, há as particularidades entre as próprias EJs, o que dificulta a proposição de um modelo detalhado e bem definido de Gerenciamento de Projetos aplicável à realidade de todas as EJs brasileiras. Para futuras pesquisas, é possível sugerir uma análise quanto aos modelos de Gerenciamento de Projetos das EJs, considerando os níveis de maturidade dessas organizações.

Revista de Gestão e Projetos - (GeP) 


\section{Referências}

Angioni, M., Carboni, D., Pinna, S., Sanna, R., Serra, N., \& Soro, A. (2006). Integrating XP Project Management in Development Environments. Journal of Systems Architecture, 52(11), 619-626. https://doi.org/10.1016/j.sysarc.2006.06.006.

Aranyossya, M., Blaskovicsa, B., \& Horváth, A. A. (2018). How Universal are IT Project Success and Failure Factors? Evidence from Hungary. Information Systems Management, 35(1), 15-28. https://doi.org/10.1080/10580530.2017.1416 943.

Bardin, L. (2009). Análise de Conteúdo. Lisboa: Edições 70.

Barlow, J., Giboney, J., Keith, M., Wilson, D., \& Schuetzler, R. (2011). Overview and Guidance on Agile Development in Large Organizations. Communications of the Association for Information Systems (CAIS), 29(2), 25-44.

https://doi.org/10.17705/1CAIS.02902.

Berssaneti, F., Carvalho, M, \& Muscat, A. (2015) O Impacto de Fatores Críticos de Sucesso e da Maturidade em Gerenciamento de Projetos no Desempenho: um Levantamento com Empresas Brasileiras. Production, 26(4), 707-723.

Boehm, B., \& Turner, R. (2005). Management Challenges to Implementing Agile Processes in Traditional Development Organizations. Ieee Software, 22(5), 30-39. https://doi.org/10.1109/MS.2005.129.

Brasil. (2016). Lei $n^{o} 13.267$, de 06 de abril de 2016. Presidência da República. Disciplina a criação e a organização das associações denominadas empresas juniores, com funcionamento perante instituições de ensino superior. Diário Oficial da União. Brasília, DF: Secretaria Geral.

Brasil Júnior - Confederação Brasileira de Empresas Juniores. (2020a). Entre o Legado e o Sonho: Relatório de 2018. Brasil Júnior, Portal da Transparência. Recuperado de
https://drive.google.com/file/d/1wWafoPLk cTExR0HIPbgMrKJHnNW-Jhxe/view, em 25 de agosto de 2020.

Brasil Júnior - Confederação Brasileira de Empresas Juniores. (2020b). Censo \& Identidade: Relatório de 2018. Brasil Júnior, Portal da Transparência. Recuperado de https://drive.google.com/file/d/1VH7guSPR yYCLiFzPEMftx1CzNVcBZCyx/view, em 25 de agosto de 2020.

Brasil Júnior - Confederação Brasileira de Empresas Juniores. (2020c). Conheça o MEJ. Brasil Júnior, Portal da Transparência. Recuperado de https://brasiljunior.org.br/conheca-o-mej, em 25 de agosto de 2020.

Brasil Júnior - Confederação Brasileira de Empresas Juniores. (2020d). Planejamento Estratégico da Rede 2016-2018. Brasil Júnior, Portal da Transparência. Recuperado de

https://drive.google.com/file/d/1tVAnwHmu IlEJUwByw65Uf8b_pDhQ-8SA/view, em 25 de agosto de 2020.

Brasil Júnior - Confederação Brasileira de Empresas Juniores. (2014). Planejamento Estratégico da Rede 2013-2015. Brasil Júnior, Portal da Transparência. Recuperado de

https://drive.google.com/file/d/1_XEFTuxtH wCsoafJzxwS1bvlQz1v0T_W/view, em 25 de agosto de 2020.

Campos, O. V., Cunha, J. V. A. da, Barbosa, Neto, J. E. B, \& Maia, S. C. (2011). Estudos de caso, realmente são? Anais do Congresso Brasileiro de Custos (CBC), Rio de Janeiro, RJ, Brasil, 18.

Carneiro, C. (2018). O estudo de casos múltiplos: estratégia de pesquisa em psicanálise e educação. Psicologia USP, 29(2), 314-321.

https://doi.org/10.1590/0103656420170151.

Chin, G. (2004). Agile Project Management: How to Succeed in the Face of Changing 
Project Requirements. New York: American Management Association.

Diário do Comércio. (2019). Empresários juniores batem recorde e são mais de 22 mil no Brasil. Diário do Comércio Online, Recuperado de https://diariodocomercio.com.br/negocios/e mpresarios-juniores-batem-recorde-e-saomais-de-22-mil-no-brasil, em 06 de fevereiro de 2020.

Dornelas, J. C. A. (2008). Empreendedorismo: Transformando Ideias em Negócios. 3ed. Rio de Janeiro: Elsevier.

Eder, S., Conforto, E., Amaral, D., \& Silva, S. (2015). Diferenciando as abordagens tradicional e ágil de Gerenciamento de Projetos. Revisa Produção, 25(3), 482-497. https://doi.org/10.1590/S010365132014005000021 .

Ereno, D. (2013). O Futuro Agora. Pesquisa FAPESP, Empreendedorismo. Edição 212. Recuperado de https://revistapesquisa.fapesp.br/o-futuroagora/ em 25 de agosto de 2020.

Fernandes, G. F. P., \& Garcez, M.P. (2019). Contribuição da maturidade da gestão de projetos para a geração de vantagem competitiva em empresas de telecomunicações. Revista de Gestão e Projetos - GeP, 10(2), 25-39. https://doi.org/10.5585/gep.v10i2.10574.

Fernandes, N. (2015). Seis Passos para Efetivar uma Proposta Assertiva em Vendas Complexas. Startupi. Recuperado de https://startupi.com.br/2015/06/seis-passospara-efetivar-uma-proposta-assertiva-emvendas-complexas/, em 24 de agosto de 2020.

Franco, D. S., \& Seibert, A. Z. (2017). A importância da empresa júnior para uma aprendizagem andragógica. Revista Brasileira de Ensino Superior, 3(4), p.5978. https://doi.org/10.18256/24473944.2017.v3i4.2113.
Freitas, T. R. de., \& Paula, V. F. de. (2016). Maturidade em Gerenciamento de Projetos nas Empresas Juniores do Brasil. In: Anais do Simpósio Internacional de Gestão de Projetos, Inovação e Sustentabilidade (SINGEP), São Paulo, SP, Brasil, 5.

Freitas, H., Oliveira, M., Saccol, A. Z., \& Mascarola, J. (2000). O método de pesquisa survey. Revista de Administração, 35(3), p.105-112.

Gerhardt, T., \& Silveira, D. (2009). Métodos de Pesquisa. Porto Alegre: Editora UFRGS.

Gil, A. C. (2002). Como elaborar projetos de pesquisa. 4ed. São Paulo: Atlas.

Goode, W. J., \& Hatt, P. K. (1979). Métodos em pesquisa social. 7ed. São Paulo: Editora Nacional.

Guimarães, T. de A., Moreira, N. C., \& Baeta, O. V. (2013). A Negociação com Clientes em Empresas Juniores da Universidade Federal de Viçosa - Campus Viçosa/MG. Revista de Administração da UNIMEP, 11(1), 81-103. https://doi.org/10.15600/16795350/rau.v11n1p81-103.

Kiran, T. S., \& Reddyb, A. V. (2019). Critical success factors of ERP implementation in SMEs. Journal of Project Management, 4, 267-280.

https://doi.org/10.1016/j.rcim.2012.04.019.

Kerzner, H. (2001). Strategic Planing for Project Management Using a Project Management Maturity Model. New York: John Wiley and Sons.

Kerzner, H. (2006) Gestão de Projetos: as Melhores Práticas. Porto Alegre: Bookman.

Kerzner, H. (2011). Gerenciamento de Projetos: uma Abordagem Sistêmica para Planejamento, Programação e Controle. São Paulo: Blucher.

King, Z., Burke, S., \& Pemberton, J. (2005). The 'Bounded' Career: An Empirical Study of Human Capital, Career Mobility and 
Employment Outcomes in A Mediated Labor Market. Human Relations, 58(8), 981-1007.

https://doi.org/10.1177/0018726705058500.

Link, C. P., Silva, G., Barichello, R., \& Dal Magro, C. B. (2020). Fatores Críticos no Gerenciamento de Projetos Públicos Sustentáveis. Gestão e Projetos $-G e P$, 11(2) p.87-109.

https://doi.org/10.5585/gep.v11i2.17490.

Mafakheri, F., Nasiri, F., \& Mousavi, M. (2008). Project Agility Assessment: An Integrated Decision Analysis Approach. Production \& Planning Control, 19(6), 567576. https://doi.org/10.1080/09537280802360884

Marcondes, A. (2017). Uma Breve História do Gerenciamento de Projetos. PMI Mato Grosso. Recuperado de http://pmimt.org.br/site/index.php/artigo/vis/ 4, em 30 outubro de 2017.

Martins, G. A. (2008). Estudo de Caso: uma Reflexão sobre a Aplicabilidade em Pesquisas no Brasil. Revista de Contabilidade e Organizações FEARP/USP, 2(2), p.8-18. https://doi.org/10.11606/rco.v2i2.34702.

Matos, F. (1997). A Empresa Júnior no Brasil e no Mundo: o Conceito, o Funcionamento, a História e as Tendências do Movimento EJ. São Paulo: Martin Claret.

McClory, S., \& Ashraf Labib, M. R. (2017). Conceptualizing the Lessons-Learned Process in Project Management: Towards a Triple-Loop Learning Framework.

International Journal of Project Management, 35, p.1322-1335. https://doi.org/10.1016/j.ijproman.2017.05.0 06.

Milosevic, D. \& Patanakul, P. (2005). Standardized Project Management May Increase Development Projects Success. International Journal of Project Management, 23(3), 181-192. https://doi.org/10.1016/j.ijproman.2004.11.0 02 .
Minayo, M. C. de S. (2001). Pesquisa Social: Teoria, Método e Criatividade. 21 ed. Petrópolis: Editora Vozes.

Mussi, R. F. de F, Mussi, L. M. P. T., Assunção, E. T. C., \& Nunes, C. P. (2019). Pesquisa Quantitativa e/ou Qualitativa: distanciamentos, aproximações e possibilidades. Revista Sustinere, 7(2), p.414-430.

https://doi.org/10.12957/sustinere.2019.411 93.

Nguyen, L. H. (2019). Relationships between Critical Factors Related to Team Behaviors and Client Satisfaction in Construction Project Organizations. Journal of Construction Engineering and Management, 145(3), 1-10. https://doi.org/10.1061/(ASCE)CO.19437862.0001620

Oliveira, R. R., \& Martins, H. C. (2020). Desempenho do escritório de Gerenciamento de Projetos: divergência de percepções entre a instrução acadêmica e a vivência profissional. Innovar, 30(75), 119 134.

https://doi.org/10.15446/innovar.v30n75.83 261.

Oliveira, R. R., Cruz, J. E., \& Oliveira, R. R. (2018). Fatores críticos de sucesso na gestão de projetos: Análise dos indicadores que constituem os predecessores da estratégia, pessoas e operações. Revista de Gestão e Projetos (GeP), 9(3), 49-66. https://doi.org/10.5585/gep.v9i3.11263.

Ortega, M. (2010). Cinco elementos essenciais para fazer uma proposta comercial. Portal Carreira \& Sucesso Catho. Recuperado de http://www.catho.com.br/carreirasucesso/colunistas/marcelo-ortega/cincoelementos-essenciais-para-fazer-umaproposta-comercial, em 24 de agosto de 2020,

Pamplona, P. \& Freitas, O. (2016). Brasil Ultrapassa Europa e se Torna Líder em Empresas Juniores no Mundo. Folha de S. Paulo, Empreendedor Social. Recuperado 
de

https://www1.folha.uol.com.br/empreended orsocial/2016/06/1752850-brasil-ultrapassaeuropa-e-se-torna-lider-em-empresasjuniores-no-mundo.shtml, em 21 de agosto de 2020,

Pant, I., \& Baroudi, B. (2008). Project management education: the human skills imperative. International Journal of Project Management, 26(2), p.124-128. https://doi.org/10.1016/j.ijproman.2007.05.0 10.

Papke-Shields, K., Beise, C., \& Quan, J. (2010). Do Project Managers Practice What They Preach, and Does it Matter to Project Success? International Journal of Project Management, 28(7), p.650-662. https://doi.org/10.1016/j.ijproman.2009.11.0 02.

Pinto, J. \& Slevin, D. (1987) Critical Factors in Successful Project Implementation. Ieee Transactions on Engineering Management, 34(1), 22-27.

PMI - Project Management Institute. (2017). A Guide to the Project Management Body of Knowledge (PMBOK guide). 6 ed, Newton Square: PMI.

Prado, D. (2002). Gerenciamento de Projetos nas Organizações. Nova Lima: Editora de Desenvolvimento Gerencial.

Rabechini, R., Jr., Carvalho, M, \& Laurindo, F. (2002). Fatores Críticos para Implementação de Gerenciamento por Projetos: o Caso de uma Organização de Pesquisa. Revista Produção, 12(2), 28-41. https://doi.org/10.1590/S010365132002000200004 .

Rabechini, R., Jr. \& Carvalho, M. (2005). Construindo Competências para Gerenciar Projetos: Teoria e Casos. São Paulo: Atlas, 2005.

Salomão, M. (2014). Evento marca 25 anos de empresas juniores no Brasil e 10 anos de Brasil Júnior. Pequenas Empresas \& Grandes Negócios. Recuperado de
http://revistapegn.globo.com/Revista/Comm on/0,,ERT329365-17180,00.html, em 25 de agosto de 2020.

Sanchez, H., \& Robert, B. (2010). Measuring Portfolio Strategic Performance Using Key Performance Indicators. Project Management Journal, 41(5), p.64-73. https://doi.org/10.1002/pmj.20165.

Santos, N. C. dos, Francischetti, C. E., Sacomano, C., Neto, Padoveze, C. L., \& Spers, V. R. E. (2013). Modelo EconômicoContábil-Financeiro para Diagnóstico Organizacional. Revista de Administração da UNIMEP, 11(2) maio/agosto, p.119-142. http://dx.doi.org/10.15600/16795350/rau.v11n2p119-142.

Serviço Brasileiro de Apoio às Micro e Pequenas Empresas (Sebrae). (2019). Empreendedorismo atrai 52 milhões de brasileiros em 2018. Agência Sebrae de Notícias, Economia. Recuperado de http://www.agenciasebrae.com.br/sites/asn/u f/NA/empreendedorismo-atrai-52-milhoesde-brasileiros-em2018,74ec85e533629610VgnVCM1000004 c00210aRCRD, em 25 de agosto de 2020.

Söderlund, J., \& Lenfle, S. (2013). Making Project History: Revisiting the Past, Creating the Future. International Journal of Project Management, 31(5), 653-662. https://doi.org/10.1016/j.ijproman.2013.02.0 05.

Souza, T., \& Gomes, C. (2015). Estudo Bibliométrico dos Principais Modelos de Maturidade em Gerenciamento de Projetos. Perspectivas em Gestão \& Conhecimento $P G \& C, 5,5-26$.

Sinesilassie, E. G., Tabish, S. Z. S., \& Jha, K. N. (2017) Critical factors affecting schedule performance: $s$ case of Ethiopian public construction projects - engineers' perspective. Engineering, Construction and Architectural Management, 24(5), 757-773. https://doi.org/10.1108/ECAM-03-20160062.

Vieira, E. (2002). Gerenciando Projetos na Era de Grandes Mudanças: uma Breve 
Abordagem do Panorama Atual. PMI

Journal, 3(PMI-RS), 7-16.

Zhang, Q., Yang, S., Liao, P-C, \& Chen, W. (2020) Influence Mechanisms of Factors on Project Management Capability. Journal of Management in Engineering,36(5), 1-15. https://doi.org/10.1061/(ASCE)ME.19435479.0000812 .

Ziliotto, D., \& Berti, (2012). A Aprendizagem do Aluno Inserido em Empresa Júnior. Revista Conexão da UEPG, 8(2), 210-217.
Williams, P., Ashill, N. J., Naumann, E., \& Jackson, E. (2015). Relationship Quality and Satisfaction: Customer-Perceived Success Factors for On-Time Projects. International Journal of Project Management, 33(8), p.1836-1850.

https://doi.org/10.1016/j.ijproman.2015.07.0 09.

Yin, R. K. (2001). Estudo de caso: planejamento e métodos. 2 ed. Porto Alegre: Bookman. 